\title{
Exploring the Learning Motivation and Effectiveness of Applying Virtual Reality to High School Mathematics
}

\author{
Yi-Chen Hsu \\ Department of Digital Technology Design, National Taipei University of Education, Taiwan \\ Received November 10, 2019; Revised December 10, 2019; Accepted December 24, 2019
}

Copyright $\bigcirc 2020$ by authors, all rights reserved. Authors agree that this article remains permanently open access under the terms of the Creative Commons Attribution License 4.0 International License

\begin{abstract}
Nowadays, it is an era of knowledge explosion. All countries in the world have already planned education in the direction of integrating information technology into teaching. Therefore, the application of information technology in education has become a global teaching trend. The purpose of this study is to integrate the virtual reality (VR) of information technology into the teaching of system of linear equations in three unknowns in high school mathematics and to explore the learning motivation and effectiveness of students after digital teaching. In this study, a quasi-experimental research design and questionnaire survey method was used to design a set of high school mathematics VR tutorial material. The system of linear equations in three unknowns was used as the learning content, and only the experimental group students were used to adopt the VR and the traditional teacher's teaching method. Before and after the experiment, the subjects were filled out with the ARCS Model and the Bloom's taxonomy which analyzed and discussed in a quantitative way, and conducted simple interviews with the subjects and the teachers to collect and analyze the data in a qualitative manner. It is found from the experimental results that the VR has the effect of improving students' learning motivation and learning effectiveness in the digital teaching of mathematics.
\end{abstract}

Keywords Virtual Reality, Integrating Information Technology into Teaching, Tutorial Materials, System of Linear Equations in Three Unknowns

\section{Introduction}

The development of mathematics is to integrate into the natural language of life. Also, mathematical education is indispensable for cultivating the pillars of the country's future. Therefore, the way mathematics learns should be brought into learning in a way that is imaginable in natural life, and virtual reality (VR) is a technological manifestation that puts users in the virtual world. When information education enters the campus, various teaching technologies and media influence the teaching and learning methods [1]. With the development of digital technology, learning is no longer limited to paper textbooks, and how to establish effective learning of students in abstract mathematics is an important goal of this research.

\subsection{Research Background and Motivation}

Today's technology has made great progress in video media, and even applied VR technology to the auxiliary textbooks for learning, making the learning process livelier and more interesting.

This research cooperates with high school mathematics teachers. The high school teachers are responsible for the design of the teaching materials, and the part of university is responsible for developing a set of VR tutorial materials of the system of linear equations in three unknowns. Apply VR to the conception and guidance of mathematical concepts, let students understand the program of the system of linear equations in three unknowns in 3D space through VR, and arouse students' interest in mathematics learning to enhance their learning effectiveness. The teaching materials extends to the 3D geometrical surface with $M$. C. Escher's architectural illusion painting, allowing students to observe the buildings of Escher via a 3D model in a VR environment. Allow students to observe different angles to solve cognitive errors in the classroom that can only be used in 2D teaching materials. This study explores whether the integration of VR information technology into teaching is suitable for the teaching of the system of linear equations in three unknowns in high school mathematics. Furthermore, whether this type of tutorial materials can stimulate students' curiosity in mathematics and actively learn, and then enhance their learning effectiveness.

\subsection{Research Questions}

This study integrates VR into the teaching the system of 
linear equations in three unknowns in several disciplines to explore the following research questions:

1. Is the VR suitable for the system of linear equations in three unknowns of high school mathematics?

2. When VR be integrated into the system of linear equations in three unknowns of high school mathematics, can students improve their learning motivation?

3. When VR be integrated into the system of linear equations in three unknowns of high school mathematics, can students improve their learning effectiveness?

\subsection{Research Hypothesis}

The VR digital tutorial materials established in this study are designed to solve the cognitive errors caused by the use of $2 \mathrm{D}$ teaching materials in the classroom. Therefore, it should be possible for students to fully understand the planes formed by the eight different intersecting situations formed by the three ternary equations in the VR environment, and indirectly affect the students' learning effectiveness. The research hypothesis is as follows:

1. VR is suitable for the system of linear equations in three unknowns of high school mathematics.

2. When VR be integrated into the system of linear equations in three unknowns of high school mathematics, students improve their learning motivation.

3. When VR be integrated into the system of linear equations in three unknowns of high school mathematics, students improve their learning effectiveness.

\section{Literature Review}

For the needs of research, this paper explores the four aspects of information technology integration into teaching, virtual reality, learning motivation and learning effectiveness through existing literature and technology.

\subsection{Information Technology Integration into Teaching}

In recent years, under the influence of constructive learning theory, the goal of computer-aided learning is no longer just to encourage students to participate unilaterally, but to hope that students can control their own learning content. Students will develop active internal learning motivations, and will be able to clarify, summarize, and change the original myths in the core concepts of the curriculum. They will find the organizational structure implied in the learning materials and construct their own basic concepts [2]. Also, the development of cognitive theory has also promoted the application of interactive simulation in education [3]. A new generation of information science teaching methods combines digital tools for education, digital media and human-computer interaction. In addition to the concept of human-computer interaction and cooperative learning, it also leads interactive technology and develops a model that adapts to multi-person participation, potentially enhancing social interaction.

The integration of information into teaching can stimulate learning motivation and quickly share teaching materials to others. The application method is not only limited to computer or software applications, but integrates technology into various teaching resources to accelerate teachers' teaching skills and students' learning ability. The use of information technology in education is more widely known as the application of contextual learning in VR. In recent years, there have been many applications, especially in computer science education. This study allows students to clearly see the illusion of simulations and eight different intersecting situations formed by three planes (as Figure 1) in VR. Provides information and geometry that teachers and students hard to imagine in 2D teaching materials.

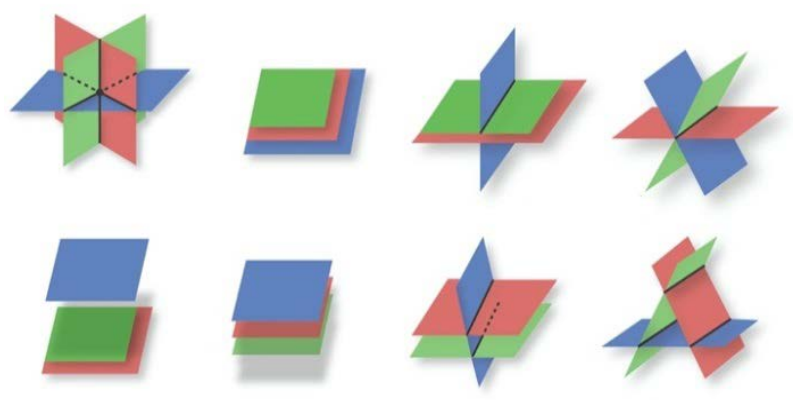

Figure 1. Eight intersecting situations formed by three planes

\subsection{Virtual Reality}

VR is a virtual world that uses computer simulation to generate 3D space, providing users with simulations of visual and other senses, making the user feel as if they are immersed. VR enables us to get a near-realistic simulation experience and create scenes that are impossible to reach in the real world, and allowing us to effectively reduce the dangers that may be encountered in the real world [4]. Burdea [5] pointed out that VR is a computer-generated program that simulates and interacts instantly with a variety of sensory information. It is a complex with three characteristics of "Immersion", "Interaction" and "Imagination" (Figure 2).

As the cost of VR experience has gradually decreased, it has gradually become mainstream. Many large technology companies have successively launched VR devices, and they have also developed in many industries, such as medicine, architecture, entertainment, and tourism. Therefore, this study also combines digital teaching with VR technology to design a set of VR digital tutorial 
materials for students to explore the system of linear equations in three un-knowns.

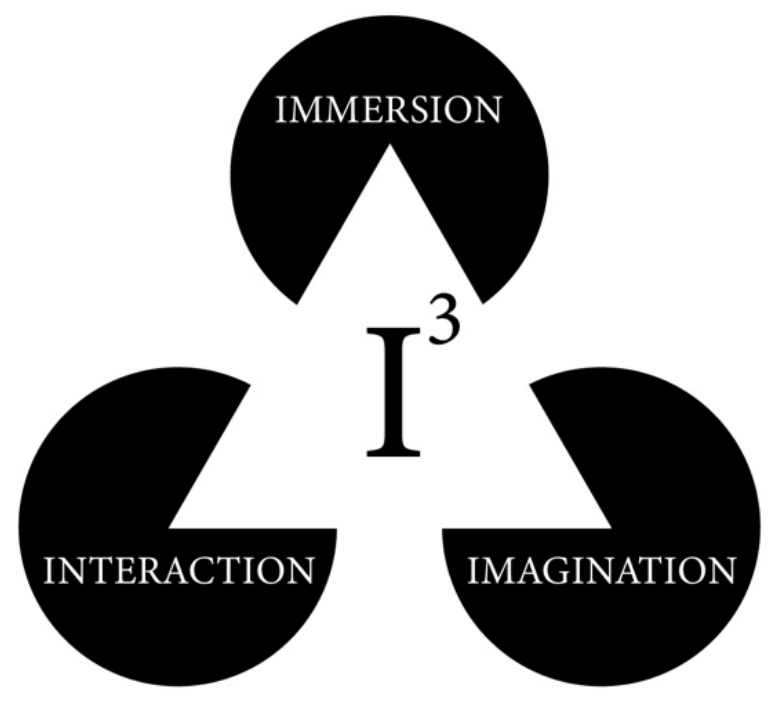

Figure 2. Virtual Reality Triangle [5]

\subsection{Learning Motivation}

Motivation plays an important role in influencing learning and achievement [6]. In recent years, in order to improve students' learning motivation and enhance the effect of learning, various teaching designs and situational creations have emerged at the educational scene. Liu et al. [7] use media technology to enhance problem-solving situations to increase student interest; The results of the study prove that the problem-solving situation of joining the media and cooperative learning does motivate students' motivation and help them to conduct self-directed learning. The student's motivation score also significantly predicts the scores of his scientific knowledge, which proves that the student's learning motivation not only ensures that the learner can fully complete the task, but also can acquire skills or knowledge content. This has important significance in science education.

The ARCS model is based on Keller's systematic design model [8] that motivates students to learn motivation. The design of this model is based on the learner's motivation, and the learner's motivation is the focus of instructional design. There are four components of ARCS model, and stands for Attention, Relevance, Confidence, and Satisfaction [8]. Furthermore, this study uses the ARCS model to identify and understand the design strategies of students' motivational needs, and adopts this scale to measure student learning motivation.

\subsection{Learning Effectiveness}

Learning Effectiveness refers to the performance of a form of test after a learner participates in a learning activity for a period of time. The widely recognized learning outcomes are based on a variety of assessment methods to understand the level of teaching goals achieved by the students and the teaching results achieved by the teachers.

Bloom's taxonomy [9] is a classification of educational learning goals set by educators for students. The cognitive domain in this taxonomy is intended to verify the cognitive level of students during the written test. The famous Bloom's taxonomy consists of six levels i.e. knowledge, comprehension, application, analysis, synthesis and evaluation.

This study adopts the learning goals of the first four levels of knowledge, comprehension, application and analysis for the teaching objectives and learning process. It also designs these four levels of questions in the learning effectiveness questionnaire.

\section{Research Method}

In this study, quasi-experimental design and questionnaire survey were used to collect the data needed for the study. In order to avoid the imbalance of the information to be taught, the control group was not used, and only the experimental group was administered to collect experimental data. The experimental teaching process accepted by each subject is the same (show as Figure 3). First, fill in the pre-test questionnaire, then enter the two VR teaching units (VR Full launch, VR 3planes), then import the teacher's traditional teaching, and then enter the two VR test units (VR Challenges, VR Quizzes), finally, the implementation of the post-test questionnaire and the simple interview. Both the teaching material and the questionnaire design use the Keller's ARCS model [8] and the first four levels of Bloom's taxonomy [9] as research tools. After the questionnaire is collected, statistics are used to analyze the teaching system.

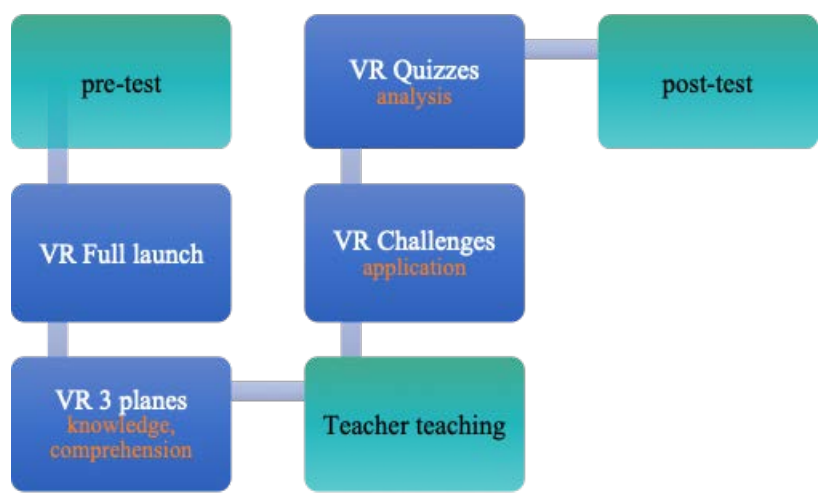

Figure 3. The experimental teaching processes

\subsection{Research Subjects}

The teaching content is "the system of linear equations in three unknowns" for high school mathematics, so the high-school students who have not studied the system of 
linear equations in three unknowns in the second year of high school are the experimental subjects. A total of 30 people were tested, with a total of 24 males and 6 females. The experiment time is about 15 minutes for the pre-test, about 30 minutes for the two VR teaching units, about 40 minutes for the teacher teaching, about 30 minutes for the two VR test units, and about 25 minutes for the post-test and interview. There is also a break of 10 minutes, and the total test time is about 150 minutes.

\subsection{Research Tools}

In response to Taiwan's K-12 high school mathematics subject, "2-3 the system of linear equations in three unknowns: judging that the three planes are at one point, in a straight line, and there is no common intersection.” We worked with high school mathematics teachers to develop a set of VR mathematics tutorial materials. The teaching goal is to enable students to achieve the following three points: 1. Can understand the composition of the three planes; 2. Can understand the geometric relationship of the three planes; 3. Can link the geometric equations of the simultaneous equations under various geometric relationships.

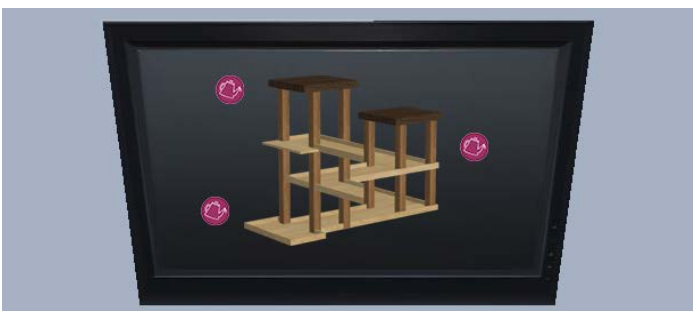

Figure 4. VR Full launch

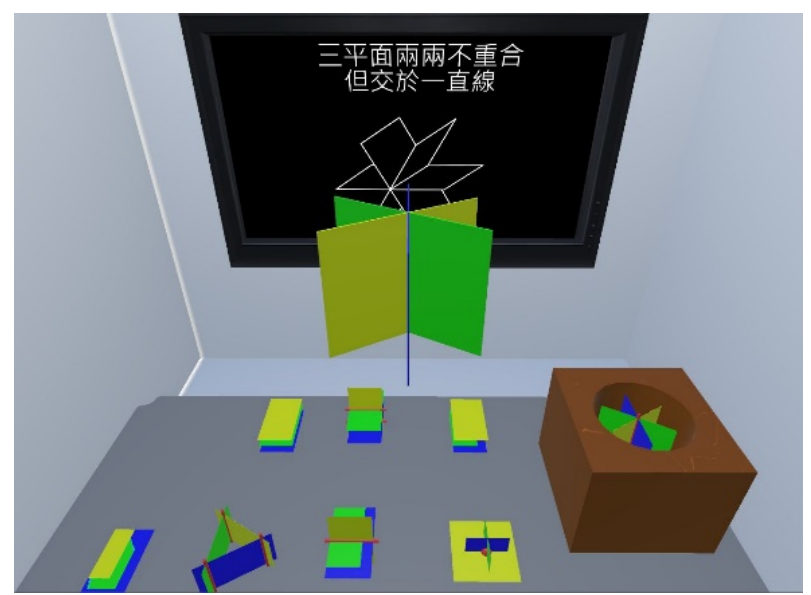

Figure 5. VR 3 planes

This research uses self-developed VR mathematics tutorial materials called "Learning stereoscopic facets from Escher's illusion "as an experimental tool. This is a set of mathematics tutorial materials for learning the system of linear equations in three unknowns from the visual simulation of the Escher's illusion geometry model. It is produced by Unity and 3Ds Max and operated on HTC VIVE. The actual operation process is 1. VR Full launch (Figure 4): Two interactive units triggered by the geometric animation of Escher's illusion to enhance students' learning motivation; 2. VR 3 planes (Figure 5) : An interactive unit consisting of eight interactive situations of three planes, allowing students to fully understand the interlaced relationship of the three planes; 3 . Teacher teaching: arrange the mathematics teachers to carry out the actual teaching of the high school the system of linear equations in three unknowns unit. The teaching content will continue to trigger the learning motivation of the VR unit before, and explain the problem-solving operation of the subsequent VR unit; 4. VR Challenges (Figure 6): Gameplay image solving unit; 5. VR Quizzes (Figure 7): Gameplay equation solving unit.

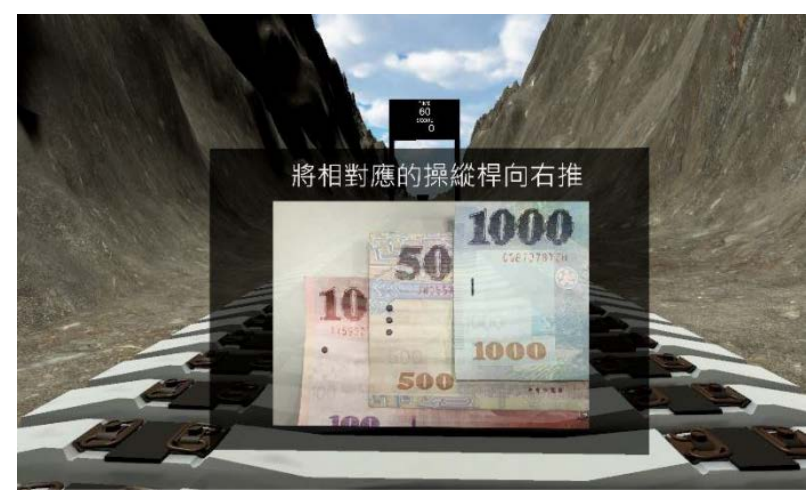

Figure 6. VR Challenges

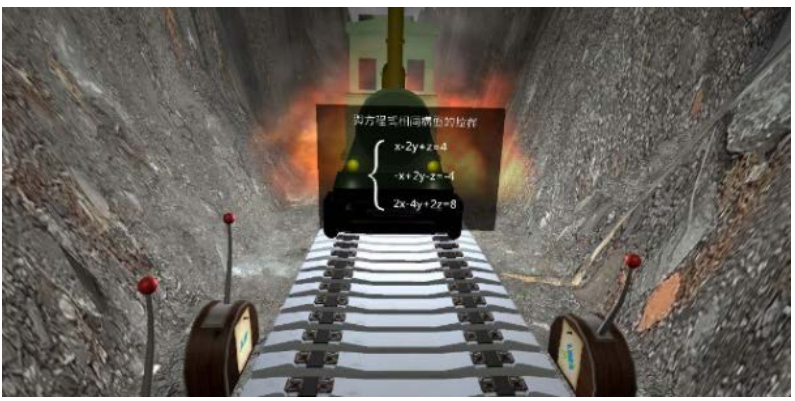

Figure 7. VR Quizzes

Questionnaires were implemented before and after the operation of the tutorial materials to collect the motivation and effectiveness of the students' the system of linear equations in three unknowns before and after the experimental teaching.

\subsection{Experiment}

The process of testing is performed for the five units described above: the first two VR units (units 1 and 2) total about 30 minutes, and the last two VR units (units 4 and 5) also total about 30 minutes. These are the VR interventional teaching units (Figure 8), students must wear the HTC VIVE helmet and hand-held handlebars. 
The researchers on the side will observe the progress of the students from the projection screen and give guidance at the appropriate time. Students can experience the stereoscopic model of Escher's illusion acuity and the compositions of three planes and its geometric relationship in the VR teaching unit, so that students can easily learn the simultaneous equations of various geometric relations. Therefore, the VR gamification test units can solve problems together with the peers, and the excellent results after the problem solving will be included in the ranking to enhance the students' sense of accomplishment.

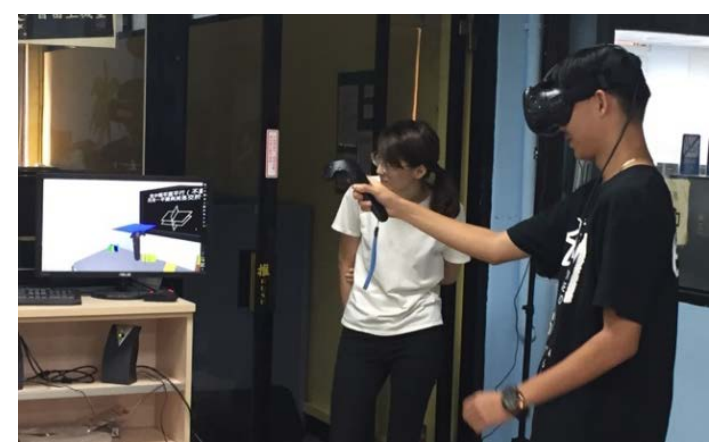

Figure 8. VR teaching unit

The teacher's actual teaching unit (unit 3) (Figure 9) imported in the middle of the teaching is about 40 minutes. This unit is the teacher's actual teaching of the system of linear equations in three unknowns. The teaching must continue the first two VR teaching contents, and prompt for the latter two VR gamification units.

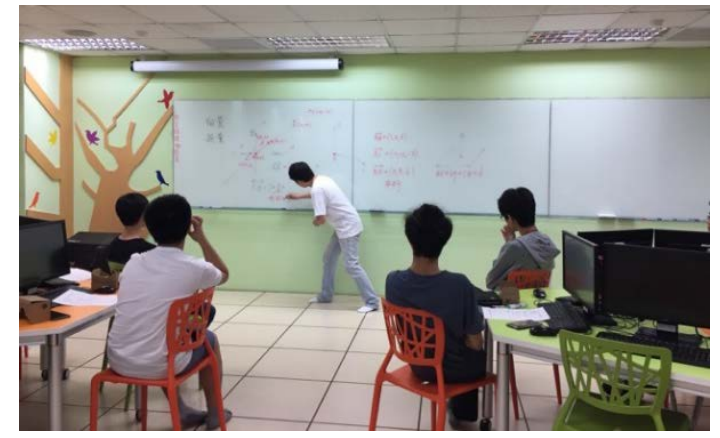

Figure 9. Teacher's actual teaching unit

The total pre-test, post-test and interview and intermission time, the overall experimental teaching experiment time is about 150 minutes.

\section{Experiment Results and Discussion}

Before and after the experiment, the subjects were asked to fill in the ARCS model and Bloom's taxonomy questionnaire of the system of linear equations in three unknowns, which were used to record and analyze the students' learning motivation and effectiveness before and after the equation.

\subsection{Subjects}

There were 30 students participating in the survey, including 24 males (80\%) and 6 females (20\%). The number of valid questionnaires for learning motivation was 23, and the number of valid questionnaires for learning effectiveness was 30 .

\subsection{Learning Motivation}

The t-test data of learning motivation of pre-test and post-test are shown in Table 1. Although the four aspects of pre-test and post-test did not show significant values, the gaps of four aspects all showed an elevated state, increased 0.25 in "Attention", 0.16 in "Relevance", 0.16 in "Confidence" and 0.34 in "Satisfaction." The results of this study show that the learning motivation in high school mathematics through VR is improved in all aspects of learning motivation. Furthermore, as shown in the results of Table 2, it can be found that the overall learning motivation is improved by 7.30 through VR tutorial materials in high school mathematics teaching, which proves that VR-assisted teaching can enhance students' learning motivation.

Table 1. t-test data of ARCS learning motivation

\begin{tabular}{|c|c|c|c|c|c|c|}
\hline & Group & $\mathrm{N}$ & Mean & Gap & $\mathrm{t}$ & $\mathrm{P}$ \\
\hline \multirow{2}{*}{ Attention } & Pre-test & 23 & 3.59 & & -1.589 & .355 \\
\hline & Post-pest & 23 & 3.84 & +.25 & & \\
\hline \multirow{3}{*}{ Relevance } & Post-pest & 23 & 3.58 & & -1.020 & .280 \\
\cline { 2 - 7 } & Post-pest & 23 & 3.74 & +.16 & & \\
\hline \multirow{2}{*}{ Confidence } & Pre-test & 23 & 3.48 & & -1.265 & .530 \\
\cline { 2 - 7 } & Post-pest & 23 & 3.64 & +.16 & & \\
\hline \multirow{2}{*}{ Satisfaction } & Pre-test & 23 & 3.54 & & -1.887 & .666 \\
\cline { 2 - 7 } & Post-pest & 23 & 3.88 & +.34 & & \\
\hline
\end{tabular}

Table 2. Gap of ARCS learning motivation

\begin{tabular}{|c|c|c|}
\hline Group & Total average & Gap \\
\hline Pre-test & 113.48 & \\
\hline Post-pest & 120.78 & +7.30 \\
\hline
\end{tabular}

\subsection{Learning Effectiveness}

In this study, the subjects were asked to fill out the Bloom's taxonomy questionnaire to analyze the learning effectiveness of high school students before and after experiencing the mathematics curriculum and incorporating VR digital materials. The pre-test and post-test questionnaire design each has 6-question multiple-choice questions, including the 4 image selection questions and the 2 formula multiple choice questions. The questionnaire was designed according to the first four levels of cognitive level of Bloom's educational goals, and 
the difficulty of the two questionnaires was confirmed consistently by high school mathematics teachers. There are 4 options for each question, and each student gets 1 point for each question. The perfect score is 6 points and the minimum is 0 points. After the experiment, the experimental data of the pre-test and post-test Bloom results obtained in this study are shown in Table 3. The average score of the pre-test is 3.7 , while the average score of the post-test is 5.3. The average improvement in learning effectiveness was 1.6 points, confirming that the teaching method of immersing in VR has improved the learning effectiveness of students in learning the system of linear equations in three unknowns.

Table 3. The average data of Bloom learning effectiveness

\begin{tabular}{|c|c|c|c|}
\hline $\mathrm{N}$ & Pre-test & Post-test & Gap \\
\hline 30 & 3.7 & 5.3 & +1.6 \\
\hline
\end{tabular}

Furthermore, after analyzing the learning effectiveness of different genders (as shown in Table 4), it is confirmed that whether boys or girls, students have improved their learning effectiveness after using VR digital materials. In particular, girls are more effective at learning than boys.

Table 4. The average data of learning effectiveness of different genders

\begin{tabular}{|c|c|c|c|c|}
\hline Gender & $\mathrm{N}$ & Pre-test & Post-test & Gap \\
\hline Boys & 24 & 3.87 & 5.37 & +1.5 \\
\hline Girls & 6 & 3 & 5 & +2 \\
\hline
\end{tabular}

\subsection{Observations and Interviews}

Most students are very excited when they first come into contact with VR. Although the teaching content is mathematics, the geometric misplaced interactive animation converted from the Escher's illusion of the first unit causes the enthusiasm of the students to challenge, and also observes and thinks that the visual influences the brain. Most of the students after the illusion of the first unit, the VR 3 planes of the second unit will actively use the rotation angle and deconstruction to observe the various configurations of the three planes, and fully understand the various interlacing situations of the three planes. Even some students feedback that they didn't expect mathematics to use illusion to introduce equations. Because they were blinded by the illusion, when they explored the composition of the three planes, they paid more attention to it and observed it. The teachers also reflected that after the students understood the eight components of the three planes through the VR, they did not have to worry about the students' inability to understand the composition of the three planes when describing the programming of linear equations in three unknowns. Students are also more interested in knowing the relationship between the VR they have just touched and the mathematical equations.

Through the simple interviews after the experiment, most students feel fresh and fun by learning mathematics in VR, and they did have access to knowledge that can help them to understand abstract mathematics. It is recommended that other units and subjects be applied in the future.

\section{Conclusions and Recommendations}

The purpose of this study is to explore the application of VR technology to assist traditional mathematics teaching and its impact on students' learning motivation and effectiveness. The teaching theme focuses on the design of teaching materials for high school mathematics the system of linear equations in three unknowns, and how to use VR to present more abstract learning themes in real life. In addition, the fun, knowledge and interaction in the learning design can be integrated, and the mathematics learning materials are more attractive to the students. From the implementation of the entire curriculum, study and analyze the impact of learning effectiveness caused by this teaching model.

After the analysis of the data and the interviews, the digital teaching materials produced in the VR combined with the traditional mathematics curriculum have a high degree of learning acceptance, and the learning motivation and effectiveness has also improved. In the future, this research will continue to optimize the teaching aids (the application of VR) so that it can be perfectly combined with traditional teaching to achieve the complementarity between the teaching staff and the teaching materials, and bring more learning benefits to the students. At the same time, students' learning motivations and effectiveness before and after the traditional teaching methods are collected to compare whether the VR assisted teaching improves the students' motivation and effectiveness.

Furthermore, because the content of this study is set to the system of linear equations in three unknowns, the results of the study are not sufficient to cover the entire high school mathematics curriculum, so subsequent related research can be applied to different units to complement the teaching content of several subjects.

\section{REFERENCES}

[1] G. Martin, P. J. Gollan, and K. Grigg. Is there a bigger and better future for employer branding? Facing up to innovation, corporate reputations and wicked problems in SHRM. The International Journal of Human Resource Management, Vol. 22(17), 2011, pp.3618-3637.

[2] H. Wang, C. Lin, C. Chao, S. Tsai, and Y. Wang. The Study of using different computer-assisted strategies to 
enhance student learning in mathematic fraction concept course. International Journal on Digital Learning Technology, Vol. 1(4), 2009, 326-346.

[3] X. Fan, and D. Geelan. Integrating information technology and science education for the future: A theoretical review on the educational use of interactive simulations. In J. Pagram \& P. Newhouse (Eds.) Proceedings of the 2012 Australian Computers in Education Conference (ACEC), pp.1-9, October 2nd-5th, 2012.

[4] W. R. Sherman, and A. B. Craig, Understanding Virtual Reality. Morgan Kaufmann. 2003.

[5] G. Burdea, Virtual Reality Systems and Applications. In Electro '93 International Conference, Short Course, Edison, NJ, pp.164-165, April 28, 1993.

[6] C. A. Ames, Motivation-What teachers need to Know. Teachers College Record, Vol. 91(3), 1990, 409-421.

[7] M. Liu, L. Horton, J. Olmanson, and P. Toprac. A study of learning and motivation in a new media enriched environment for middle school science. Educational Technology Research and Development, Vol. 59, 2011, 249-265.

[8] J. M. Keller, Strategies for stimulating the motivation to learn. Journal of Performance and Instruction, Vol. 26(8), 1987, 1-7.

[9] L. W. Anderson, D. R. Krathwohl, P. W. Airasian, K. A. Cruikshank, R. E. Mayer, R. R. Pintrich, , ... M. C. Wittrock, A Taxonomy for Learning Teaching, and Assessing: A Revision of Bloom's. New York: Longman, 2001. 